\title{
Biogeography of Camphorosmeae (Chenopodiaceae): tracking the Tertiary history of Australian aridification
}

\author{
Jonathan Cabrera ${ }^{1}$, Surrey W.L. Jacobs ${ }^{+}{ }^{\dagger}$ and Gudrun \\ Kadereit ${ }^{1}$
}

\author{
${ }^{1}$ Institut für Allgemeine und Spezielle Botanik und Botanischer Garten, Universität Mainz, Mainz, \\ 55116, Germany \\ ${ }^{2}$ National Herbarium, Royal Botanic Gardens, Sydney, New South Wales, 2000, Australia \\ Author for correspondence: jfcabrera@uplb.edu.ph
}

\begin{abstract}
Camphorosmeae (Chenopodiaceae, formerly Sclerolaeneae) are widespread across all states of Australia. Molecular data revealed that the Australian Camphorosmeae represent a monophyletic lineage comprising 147 currently recognised species, 145 of which are endemic to Australia. Like their Eurasian relatives most Australian Camphorosmeae are well-adapted to dry and saline environments, and most species are distributed in semi-arid or arid landscapes of the Eremaean area of central and western Australia. The historical biogeography of the Australian Camphorosmeae is analysed using an ETS phylogeny of the group and DIVA. We found that diversification of the tribe started at the end of the Miocene, and that radiation took place during the Pliocene, probably driven by the aridification of Australia during this time. Southern west Australia probably served as the ancestral area, and we hypothesise that the ancestors of Australian Camphorosmeae were already adapted to dry and saline conditions and might have been distributed in coastal or saline inland habitats. Successful dispersal and establishment of Camphorosmeae in the then newly developed arid regions was probably enhanced by niche pre-emption. Our timing of the radiation of this drought-adapted lineage and the directions of its dispersal support the hypothesis that the aridification of Australia started during the Late Miocene and arid areas expanded during the Pliocene from the west to the east and then north.
\end{abstract}

\section{Introduction}

Camphorosmeae are the only tribe of Camphorosmoideae (Chenopodiaceae), a subfamily most closely related to Salsoloideae (Akhani et al. 2007, Kadereit \& Freitag 2011). The tribe comprises 147 Australian species in 12 endemic and 2 introduced genera, and c. 35 extra-Australian species in 8 genera (Kadereit \& Freitag 2011). Outside

${ }^{\dagger}$ Deceased November 26, 2009. 
Australia, Camphorosmeae are distributed in southwestern Europe and northwestern Africa through the Mediterranean area and north Africa to eastern Asia. A few species also occur in South Africa and North America.

Camphorosmeae is the most diverse tribe of Chenopodiaceae in Australia. The genera Sclerolaena (64 spp.) and Maireana (57 spp.), together with Atriplex (57 native, 56 of which are endemic, and 4 introduced spp.; Chenopodioideae), contain nearly $60 \%$ of the native species of Chenopodiaceae found in Australia (Wilson 1984). The degree of endemism of Camphorosmeae is $99 \%$ compared to $80 \%$ for Australian species in general (Crisp et al. 1999). Taxa of the tribe, although mainly adapted to arid and semi-arid conditions of the Eremaean area of central and western Australia, are present in all major areas of endemism sensu Crisp et al. (1999). Several species are salt or gypsum tolerant and their occurrence is linked to inland salt lakes. Some species extend into agricultural lands and coastal habitats where they tolerate slightly saline soils. Furthermore, species distribution varies significantly. For example, Roycea spinescens is restricted to saline sand and sandy clay areas from Morawa south to Merredin, Western Australia, while the widespread species Enchylaena tomentosa occurs throughout Australia and extends beyond the continent to New Caledonia.

Recent molecular studies clearly support the monophyly of Camphorosmeae (Akhani et al. 2007, Kadereit et al. 2003, Kadereit \& Freitag 2011) as well as the monophyly of the Australian genera (Cabrera et al. 2009, Kadereit et al. 2005). The origin of the Australian Camphorosmeae has been dated to the Late Miocene (8.1-3.6 mya, Kadereit et al. 2005) and to the Middle Miocene (16.4-10.3 mya; Kadereit \& Freitag 2010), with a small clade of three annual species, Kochia melanoptera, K. krylovii and Bassia dasyphylla, distributed in Central Asia, being sister to the Australian lineage. These three Asian species are similar to the Australian species in performing $\mathrm{C}_{3}$-photosynthesis and showing a $\mathrm{C}_{3}$-sclerolaenoid leaf structure, in contrast to the majority of Eurasian species which are $\mathrm{C}_{4}$-plants (Cabrera et al. 2009). A new genus, viz. Grubovia Freitag \& G.Kadereit was recently erected to accommodate these three species (Kadereit \& Freitag 2011).

In a detailed phylogenetic and morphological study of Australian Camphorosmeae, Cabrera et al. (2009) found that the lineage represents a young group with a large number of morphologically very similar species. Several of the smaller genera are nested within Sclerolaena, and the large genus Maireana was found to be polyphyletic. The morphological delimitation of genera turned out to be extremely difficult due to the lack of phylogenetically informative characters that support deeper branches. The only informative character that delimits certain clades seems to be the morphology of the fruiting perianth (Cabrera et al. 2009). This lack of diagnostic characters at the generic level had already been recognised by Wilson (1984).

Sixty-five to 70 percent of the Australian continental land mass comprises a vast arid centre surrounded by an enormous semi-arid region (AUSLIG 1990, Barlow 1981). As much as $50 \%$ of the entire land receives effective rainfall of less than 300 millimetres per year (BOM 2010), and the whole region suffers from major irregular and periodic seasonal droughts (Hobbs et al. 1998, Nix 1981). Rainfall is the all-dominant environmental factor for most of the continent (Keast 1959). This was different at the beginning of the Tertiary when Australia had much higher levels of rainfall and was dominated by warm to temperate rainforests (Hill et al. 1999). The onset and direction of aridification in Australia has been under debate for a long time and several hypotheses have been developed (Beard 1977; Bowler 1976, 1982; Burbidge 1960; Frakes 1999; 
Markgraf et al. 1995; Martin 1978, 1998a; Quilty 1982; Stein \& Robert 1986; Zheng et al. 1998). Summarising geological and fossil evidence, Martin (2006) points out that by the Middle Miocene the climate in central Australia had changed to a seasonal climate with a well-marked hot season with high evaporation, and that in central and Western Australia the regular flow of palaeodrainage systems had stopped. These events mark the onset and expansion of arid landscapes in Australia. It is likely that the onset of aridity started earlier in the north-west than in the south-east (Martin \& McMinn 1994, Martin 1998a). During the Late Miocene, central Australia became more and more arid and dry woodlands and chenopod shrublands became major vegetation types (Martin 2006). Large quantities of the chenopod pollen type have been found in central Australia from the Pliocene onwards (Benbow et al. 1995, Martin 1998b, Singh \& Luly 1991). After a slightly wetter and warmer period at the beginning of the Pliocene, the climate has become gradually drier. From the late Miocene onwards, regular fires became a vegetation-shaping factor which favoured the expansion of grasslands, especially during the Late Pliocene (Martin 2006).

In this contribution, the historical biogeography of Camphorosmeae is used to give support to current hypotheses on the timing of the aridification of Australia during the Tertiary. The widespread distribution of the tribe, its suggested stem age, and its habitat specialisation is helpful in providing a new source of evidence for the environmental evolution of the continent. Ancestral area reconstruction with DIVA is used to provide a scenario pertaining to the onset and the direction of desertification.

\section{Methods}

\section{Phylogenetic inference}

A previous study of the Australian Camphorosmeae based on molecular sequence data provided the phylogenetic hypothesis used for the group (Cabrera et al. 2009). A matrix containing the 5' external transcribed spacer region of the nuclear rDNA (5' nrDNA ETS) sequence data from 69 species of the 12 recognised endemic genera of Camphorosmeae in Australia and two Central Asian taxa (Bassia dasyphylla and Kochia melanoptera) was used.

Phylogenetic relationships among sampled taxa were estimated using the maximum

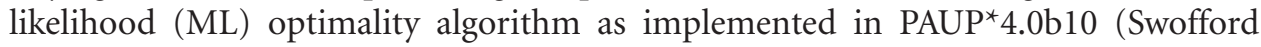
2002). The TVM+I+G model of sequence evolution and parameter settings were chosen by using the Akaike information criterion as suggested by Modeltest V3.06 (Posada \& Crandall 1998).

A likelihood ratio test as implemented in Modeltest was conducted to determine if a strict molecular clock can be enforced on the ETS sequence data for the group. In this case, the log-likelihood scores of the ML tree with and without enforced molecular clocks differed significantly, and a smoothing method was needed to determine the age of Camphorosmeae. The ML tree obtained in the absence of a molecular clock was subjected to rate smoothing applying the penalised likelihood (PL) approach using the computer software r8s v1.70 (Sanderson 2002, 2004). An optimal smoothing factor was chosen based on a data-driven cross-validation procedure implemented in r8s (Sanderson 2004). This smoothing method (Sanderson 1997, 2002) reduces 
dimensionality of a molecular clock by imposing an autocorrelation among the parameters. It allows one rate for every branch but then restricts how much difference in rate is allowed between branches. Rate smoothing by penalised likelihood (Sanderson 2002) penalises the parameter estimates of rates by comparing them with their phylogenetically immediate neighbours. In the absence of a suitable fossil to calibrate the molecular phylogeny of the Australian Camphorosmeae, estimated age of the split between the Eurasian and Australian taxa from multiple sequence data was used (Kadereit \& Freitag 2011).

Because the ML tree contained multiple zero-length branches, including the three most basal clades, separate maximum likelihood analyses on sub-sets of the ETS matrix were performed to produce a completely bifurcating tree as required by DIVA. One hundred semi-random sub-samples of 28 to 44 taxa were used for the determination of the basal clades and the resolution of several polytomies found in the ML tree. The best model of sequence evolution for each of the smaller matrices was selected using the Akaike information criterion derived by Modeltest (Posada \& Crandall 1998). Five taxa were always included in the analysis: one outgroup species and a taxon from each of the four most basal clades in the ML tree, i.e. Maireana erioclada-M. pentatropis clade, Roycea clade, M. brevifolia clade, and M. pyramidata-Eremophea clade.

\section{DIVA analysis}

Geographical areas were defined based on previously recognised bioregions in Australia (Cracraft 1991; Crisp et al. 1995, 1999). Distribution information on Camphorosmeae was taken from the Flora of Australia (Wilson 1984) and complemented by the study of c. 1700 herbarium specimens from PERTH, CANB and NSW (Table 1).

Table 1. Distribution and species number of the native Australian Camphorosmeae genera in Australia within each area of endemism. $(A=$ Kimberley; $B=$ Arnhem; $C=$ Cape York; $D=$ Atherton; $\mathrm{E}=$ Eastern Queensland; $\mathrm{F}=$ McPherson-Macleay; $\mathrm{G}=$ Southeastern New South Wales; H = Victoria; I = Eyre; $\mathrm{J}=$ Adelaide; $\mathrm{K}=$ Northern Desert; $\mathrm{L}=$ = Eastern Desert; $\mathrm{M}=$ Southwest; $\mathrm{N}=$ Western Desert; $\mathrm{O}=$ Pilbara). Distribution areas in parentheses are not part of the areas of endemism and were not included in the analyses.

$\begin{array}{ll}\text { Genera } & \text { Species sampled / Total } \\ \text { Didymanthus } & 1 / 1 \\ \text { Dissocarpus } & 2 \text { / } 4 \\ \text { Enchylaena } & 2 / 2 \\ \text { Eremophea } & 2 \text { / } 2 \\ \text { Eriochiton } & 1 / 1 \\ \text { Maireana } & 23 / 57 \\ \text { Malacocera } & 2 / 4 \\ \text { Neobassia } & 2 / 2 \\ \text { Osteocarpum } & 2 \text { / } 5 \\ \text { Roycea } & 2 / 3 \\ \text { Sclerolaena } & 29 / 64 \\ \text { Threlkeldia } & 1 / 2\end{array}$

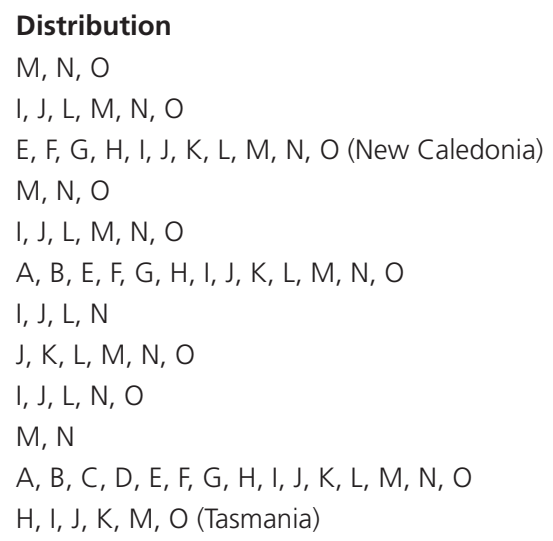


In order to reconstruct the biogeographical history of Camphorosmeae, dispersalvicariance analysis (DIVA) was performed using DIVA 1.1a (Ronquist 1996, 1997). Since vicariance is the default mode of speciation recognised by the program, optimisation was conducted with the maximum number of ancestral areas set to two to favour dispersal rather than vicariance (Donoghue et al. 2001; Ronquist 1996, 1997; Zink et al. 2000). This mode of analysis also helps to identify the possible geographical distribution of the ancestors of the group (Zink et al. 2000).

\section{Results}

The cross-validation procedure implemented in the program r8s (Sanderson 2004) using the penalised likelihood algorithm resulted in a smoothing value of 100000 . The penalised likelihood chronogram (i.e. the "smoothed" ML tree) showing the relative minimum ages of the Australian Camphorosmeae clades using age estimates for the split between the Australian Camphorosmeae and its sister group in Central Asia is shown in Fig. 1. The age of the split between the Australian clade from the Central Asian clade was dated to 16.4-10.3 mya based on fossil-calibrated age estimates using $n d h \mathrm{~F}$, $r b c \mathrm{~L}$ and $a t p \beta-r b c \mathrm{~L}$ spacer sequence data (Kadereit \& Freitag 2011). The chronogram in Fig. 1 shows that the majority of lineages arose during the Pliocene. By the end of the Pliocene c. 1.8 mya, there was a 3.25-fold increase in diversity compared to the diversity at the end of the Miocene (based on a pure-birth model).

Dispersal-vicariance analysis required a completely bifurcating tree. Since the maximum likelihood tree was not completely resolved, a modified likelihood tree derived from multiple ML analyses of sub-samples of the ETS matrix was used for this test (Fig. 2). The robustness of the basal clades and relationships among taxa in polytomies was tested by redundant sub-sampling and re-sampling of the accessions. The clade containing Maireana erioclada was resolved as the most basal clade in the Australian Camphorosmeae in $70 \%$ of the replicates. The Maireana brevifolia clade was resolved most basal only $16 \%$ of the time, and $14 \%$ of the total replicates showed a basal polytomy.

Dispersal-vicariance analysis of Camphorosmeae resulted in an exact solution when the maxareas option was set to two. This result suggested three alternative ancestral distributions for the root of the Australian Camphorosmeae (Fig. 2): (1) the Southwest endemic region, (2) the South-west and the Western Desert regions combined, and (3) the South-west and the Pilbara regions.

DIVA implied an initial eastward range expansion from the Southwest, into the Eastern Desert region, followed by the occupation of the central southern coast of the continent into the Eyre and Adelaide zones. Further dispersal into the southeastern regions of Australia, i.e. into eastern Queensland, McPherson-Macleay, south-eastern New South Wales and Victoria, prior to a northward expansion was also suggested by DIVA (Fig. 3).

The northern tropical regions of Australia did not belong to the possible ancestral areas of Camphorosmeae, suggesting that the presence of the plant group in these areas is a result of recent dispersal/expansion. 


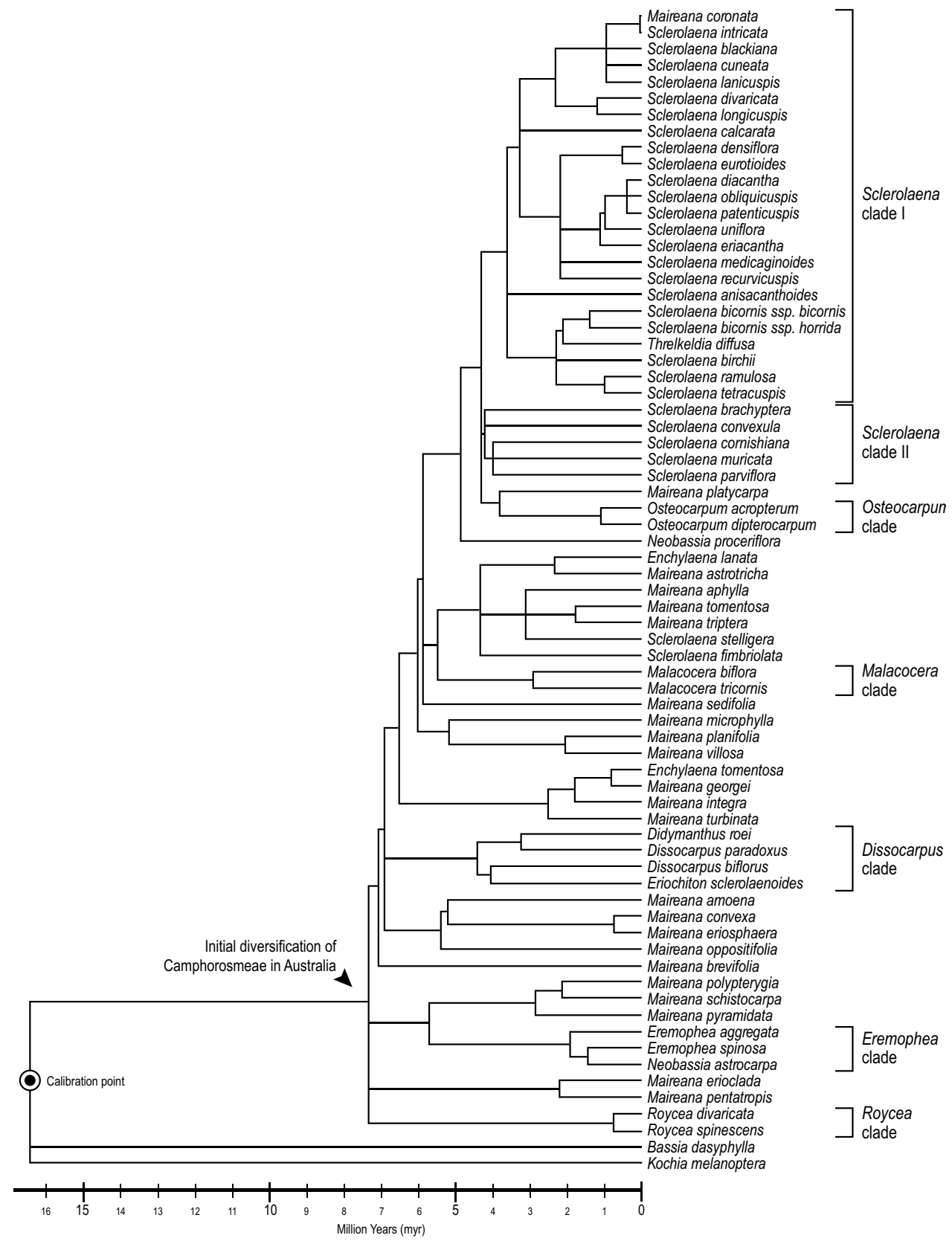

Fig. 1. Relaxed maximum likelihood (ML) tree of the Australian Camphorosmeae with estimated ages derived from divergence time analysis of the ETS sequence data using a relaxed clock method implementing penalised likelihood. For calibration the split between the Australian Camphorosmeae and its Central Asian sister was set to 16.4-10.3 mya according to Kadereit \& Freitag (2011). 


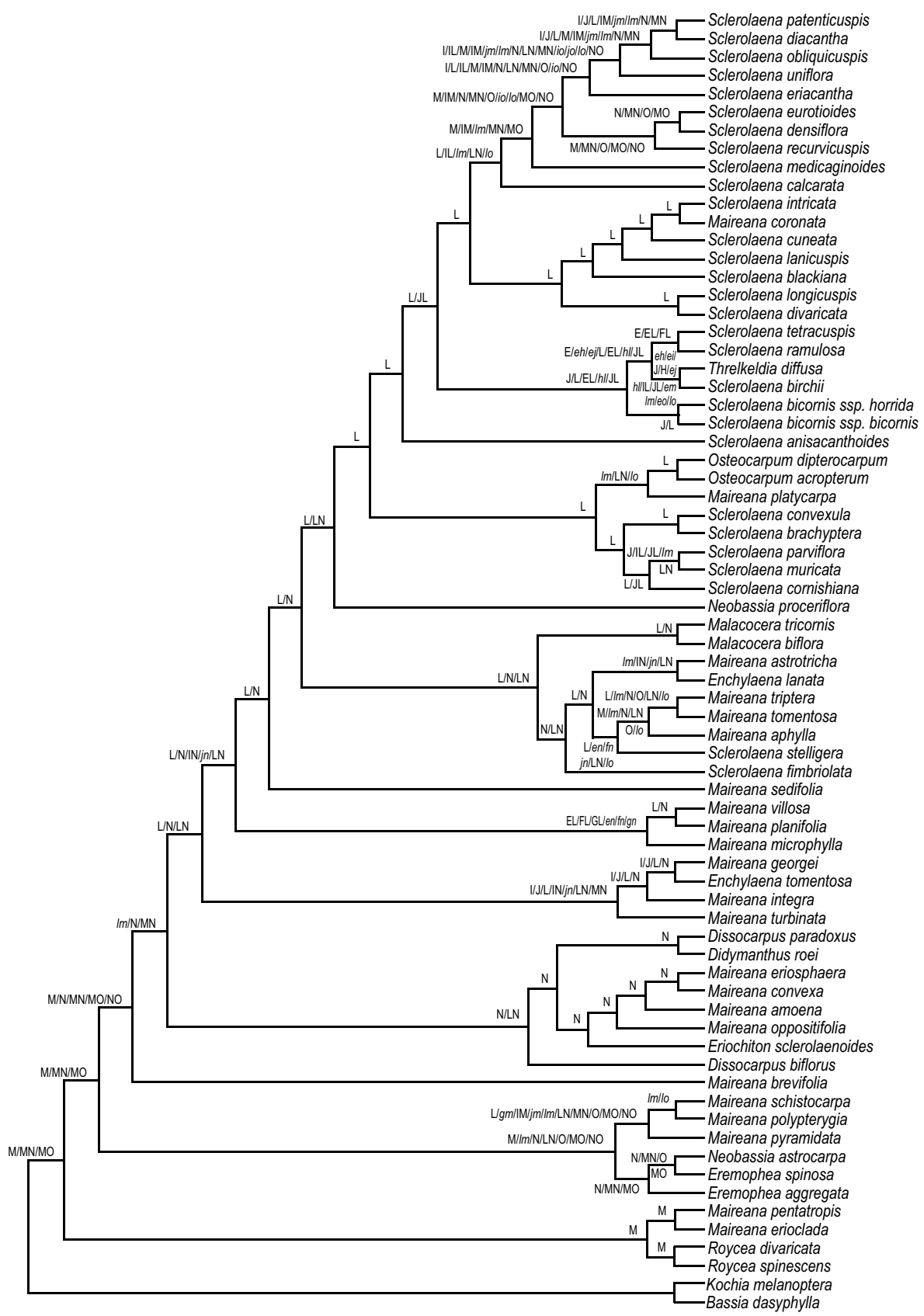

Fig. 2. The exact biogeographic solution using dispersal-vicariance analysis (DIVA). Possible ancestral centers of endemism are shown on the nodes of the cladogram. Solutions in uppercase are adjacent regions, and represent the preferred solutions with the assumption that dispersal is the main mode of distribution. Physically non-adjacent solutions are written in italicised lowercase. $(\mathrm{E}=$ Eastern Queensland; F = McPherson-Macleay; $\mathrm{G}=$ Southeastern New South Wales; $\mathrm{H}=$ Victoria; $\mathrm{I}=$ Eyre; $\mathrm{J}=$ Adelaide; $\mathrm{L}=$ Eastern Desert; $\mathrm{M}=$ Southwest; $\mathrm{N}$ = Western Desert; $\mathrm{O}=$ Pilbara) 


\section{Discussion}

Australian Camphorosmeae split from their Central Asian sister group in the midMiocene (16.4-10.3 mya) according to Kadereit \& Freitag (2011). Some time between this split and the initial diversification of the lineage during the Late Miocene it must have reached Australia (Fig. 1). From this presumably single colonisation event the lineage succeeded in occupying all floristic regions of the continent and gave rise to the 147 currently recognised species (Figs $2 \& 3$ ). Our biogeographical analysis is hampered by the relatively low resolution of the ETS tree and by the incomplete sampling of the lineage (69 of 147 species representing all 12 endemic genera). By sampling all genera and including several accessions from the large genera, Sclerolaena and Maireana, we believe, however, that we have adequately represented the morphological and biogeographical diversity of the lineage. Since the molecular marker used here is among the most variable markers used in phylogenetic studies (e.g., Bayer et al. 2002) and has proved to be informative at the infrageneric level in Chenopodiaceae (e.g., Kadereit et al. 2007; Zacharias \& Baldwin 2010) we assume that the low resolution of the molecular tree may be caused by the relatively young and fast radiation of the group. The application of a number of variable cpDNA markers and ITS did not add resolution to the ETS data set (Cabrera et al. 2009).

\section{Arrival of Camphorosmeae in Australia}

At the time of arrival of Camphorosmeae in Australia (sometime during the Middle to Late Miocene; Kadereit et al. 2005, Kadereit \& Freitag 2011) the continent had already separated from the remainder of the landmasses of the Southern Hemisphere (Kuhnt et al. 2004; McLoughlin 2001; Stagg \& Willcox 1992; Veevers 1986, 2000). This suggests that ancestors of the group must have arrived in Australia via long-distance dispersal, likely from temperate semi-arid to arid parts of continental Eurasia, the region where the closest relatives are widespread today. Accordingly, they are not of Gondwanan origin as had been suggested by Carolin (1981). The results of the biogeographical analyses reject the possibility that Camphorosmeae migrated via tropical Southeast Asia and entered the continent from the north. The DIVA analysis shows that early colonised areas are clearly located in the south and west of the continent, and the tropical north was reached only very recently (Figs $3 \& 4$ ).

Several workers on Australian biogeography have suggested that progenitors of the arid flora of Australia, including Chenopodiaceae, were already present on the continent before the onset of aridification some 10-15 mya (Burbidge 1960, Beadle 1981, Christophel 1989, Schodde 1989, Martin 2006). We believe that this was the case in Camphorosmeae and we hypothesise that the progenitors of modern Australian Camphorosmeae were already adapted to arid and saline environments. Other members of the tribe in Eurasia and elsewhere are adapted to such conditions, and this character must have developed early in the evolutionary history of the whole tribe. Not only Camphorosmoideae but also its sister group Salsoloideae consist of species that are adapted to semi-arid and arid habitats, and tolerate variable degrees of salinity. The assumption that adaptation to arid conditions is the plesiomorphic condition in Camphorosmoideae is further supported by hypotheses about the onset of aridification of continental Asia, which has been estimated to have taken place at the beginning of the Miocene c. 22 mya (Guo et al. 2002). This coincides with the initial diversification of Camphorosmoideae (Kadereit \& Freitag 2011) and clearly predates the arrival of the 

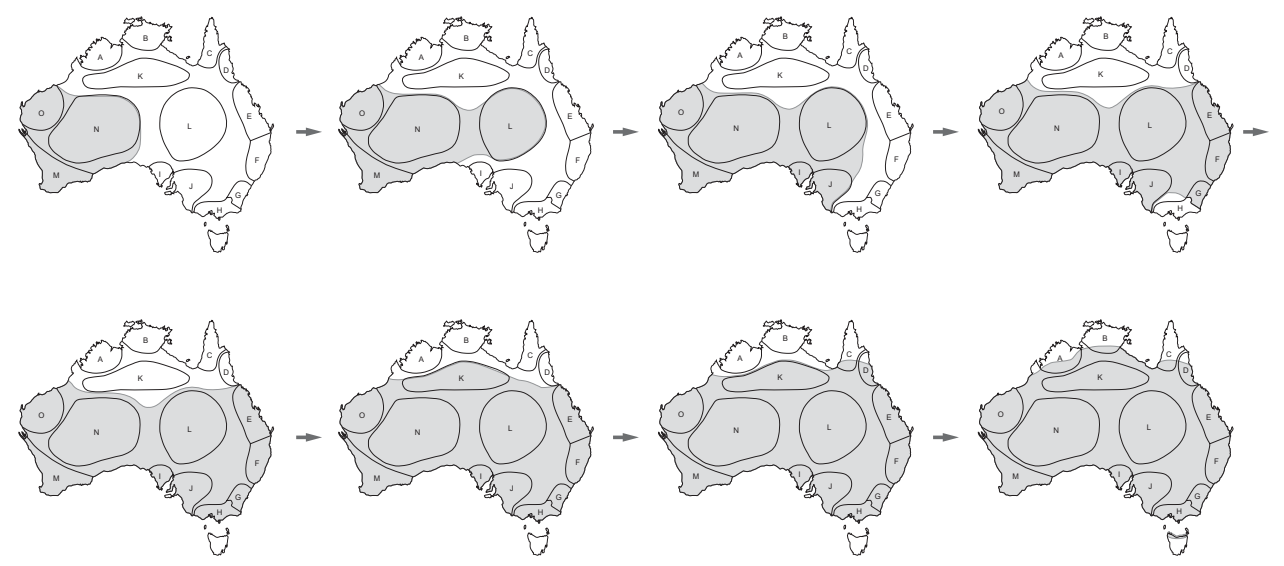

Fig. 3. Map of Australia with regions of endemism and the sequence of range expansion according to the DIVA analysis. $(\mathrm{E}=$ Eastern Queensland; F = McPherson-Macleay; $\mathrm{G}=$ Southeastern New South Wales; $\mathrm{H}=$ Victoria; $\mathrm{I}=$ Eyre; $\mathrm{J}$ = Adelaide; $\mathrm{K}=$ Northern Desert; L = Eastern Desert; $\mathrm{M}=$ Southwest; $\mathrm{N}=$ Western Desert; $\mathrm{O}=$ Pilbara)

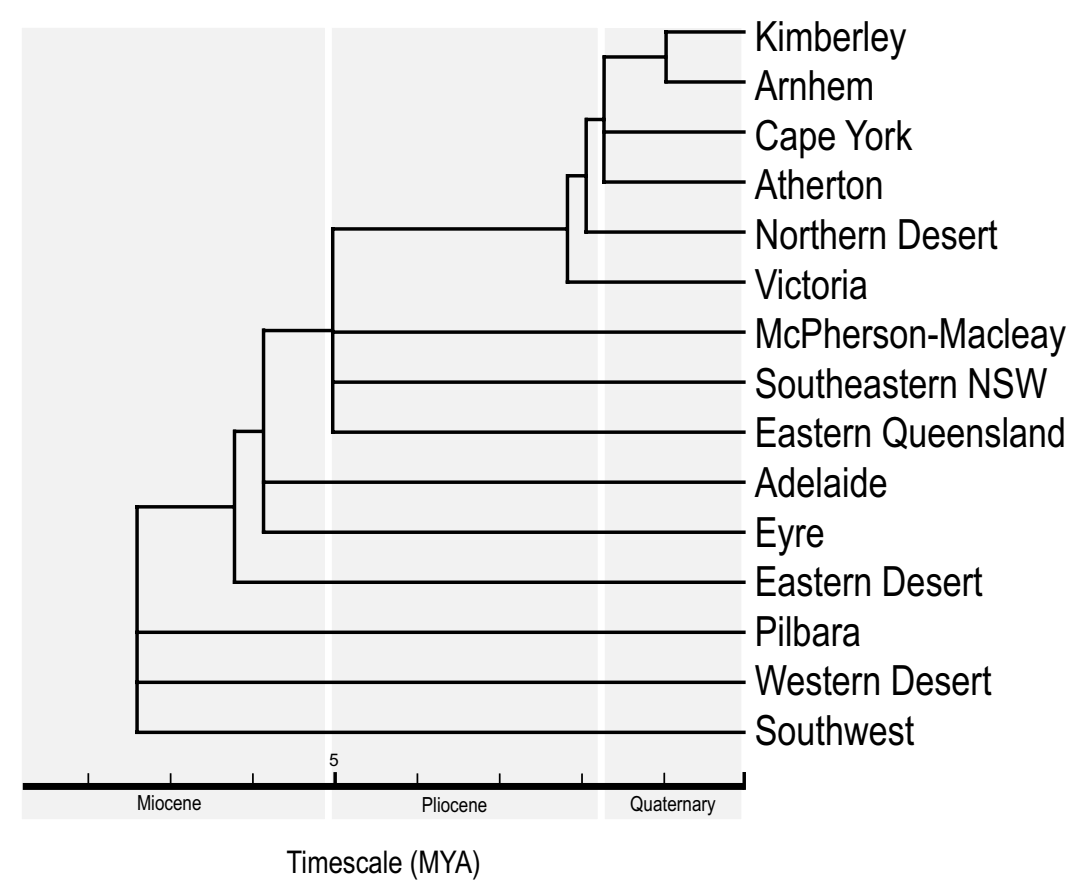

Fig. 4. General area relationships derived from dispersal vicariance analysis showing possible ages of colonisation of the current distribution areas. 
tribe in Australia. The progenitors of modern Australian Camphorosmeae might have colonised coastal habitats or suitable disturbed and probably saline inland habitats before the onset of aridification. The long period of time between the split of the ancestral Camphorosmeae from the Eurasian relatives and the onset of diversification within Australia (Fig. 1) suggests that the environmental conditions necessary to promote diversification in the group may not yet have existed upon their arrival.

\section{Diversification of Camphorosmeae in Australia}

The timing of initial diversification of Camphorosmeae during the Late Miocene coincides with several hypotheses about the onset of aridity in Australia (Beard 1977; Bowler 1982; Markgraf et al. 1995; Martin 1998a, 2006; Stein \& Robert 1986). The DIVA analysis showed that the most probable ancestral area of endemism of Camphorosmeae in Australia was along or near the southwestern coast of the continent (Figs 3 \& 4). Barlow's (1981) hypothesis that Chenopodiaceae may actually have radiated from within the arid zone, i.e. central Australia, is thus not corroborated by the biogeography of Camphorosmeae presented here. Furthermore, the DIVA analysis showed that from the south-west, there was a multidirectional radiation into the neighbouring regions: first to the Eastern Desert region then to the south into Eyre and Adelaide regions, and then into the southeastern regions of Australia (i.e. into eastern Queensland, McPherson-Macleay, southeastern New South Wales and Victoria) and, finally the interzones of tropical northern Australia (Fig. 3). In Australia, there are no significant geological features to prevent continuous migration within the continent (Barker \& Greenslade 1982, Byrne \& Hines 2004). Therefore, Camphorosmeae likely had the possibility to migrate into neighbouring regions as soon as favourable habitats opened up.

Deeper-level diversification within the Australian Camphorosmeae may have been rapid. By the end of the Pliocene, c. 1.8 mya, more than $70 \%$ of the investigated lineages already existed. These lineages represent an almost 250\% diversity increase between the end of the Miocene and the onset of the Quaternary. If correctly dated, this period concurs with the onset and persistence of Australian aridification based on Bowler (1982). According to his investigations on weathering profiles of lake sediments, the continent experienced a period of sustained aridity starting c. 6 mya and continuing to about 2.5 mya.

In summary, we hypothesise that Camphorosmeae radiated, concurrently with the development of the arid regions, from the south-west of the continent eastand northwards, starting in the Late Miocene. There was enhanced diversification during the Pliocene (Figs $3 \& 4$ ) and most lineages of the present day Australian Camphorosmeae already existed during this epoch (at least $70 \%$ of the sampled taxa). During this period all but the northern regions (Kimberley, Arnhem, Cape York and Atherton) were reached (Figs $3 \& 4$ ). As favourable ecological opportunities opened up, Australian Camphorosmeae dispersed in to the newly developed niches. We assume, however, that climatic oscillations during the Pliocene and Pleistocene have also greatly influenced the biogeography of the group. Evolving lineages have probably reduced their distribution to relictual areas as the arid zones contracted. It is possible that frequent shifts in distribution admixed taxa that had been separated before and have complicated the recent phylogenetic history of the lineage. 


\section{Drawbacks of DIVA and age estimates}

One major drawback of DIVA is that it underestimates dispersal because sister taxa having the same areas of distribution are assumed to be derived from a common ancestor that speciated through vicariance simultaneously in all areas (Voelker 1999). Similar to the problem of morphological or molecular homology, the case of parallel dispersals could also account for similarities in distributions and not common ancestry. Another problem lies with the reconstruction of ancestral areas when different descendants occupy different areas (Drovetski 2003). DIVA favours a widespread ancestor present in all areas occupied by its descendant species, forcing an unrealistic assumption that an ancestor had a much wider distribution than any of its descendants (Ronquist 1997). It is unlikely that the ancestral distribution of Camphorosmeae in Australia was widespread, and thus vicariance could not account for the current distribution of the group. In this case, DIVA was set to resolve a maximum of two ancestral areas per node to favour dispersal. This led to the identification of sequential migration events (as opposed to sequential vicariance events) for the ancestors of the tribe. Migration would have favoured dispersal scenarios between adjacent areas. Kimberley, Arnhem, Cape York and Atherton were colonised most recently since these are non-arid regions, and the presence of Camphorosmeae here is limited to the interzones (Wilson 1984).

The age estimates provided here present only a rough estimate since direct fossil evidence is lacking and the rate smoothing applied here might over- or underestimate mutation rates in certain lineages. Nevertheless, our dating did not produce ages that conflict with the fossil record for Chenopodiaceae in Australia. The earliest chenopodlike pollen fossils were dated from the Oligocene-Miocene boundary (Martin 1981, Christophel 1989). It is not clear that these fossils belong to Chenopodiaceae as they might also belong to Amaranthaceae or Caryophyllaceae which have similar pollen morphology. If they belong to Chenopodiaceae they might represent fossils of the earliest Australian chenopod lineage, Scleroblitum (Kadereit et al. 2005). From the Pliocene onwards, larger quantities of the chenopod pollen type were found in central Australia (Benbow et al. 1995, Martin 1998b, Singh \& Luly 1991) which matches with the diversification of Camphorosmeae during this time. However, these large quantities of chenopod-like pollen could also be the result of the spread of Atriplex communities in central Australia. Like Camphorosmeae, Atriplex started to diversify in Australia during the Late Miocene/Early Pliocene (Kadereit et al. 2010).

\section{Acknowledgments}

We wish to thank Joachim Kadereit (Mainz) for a number of helpful suggestions which greatly improved the manuscript. We thank the German Science Foundation (DFG), the University of Mainz and the German Academic Exchange Service (DAAD) for financial support. We are very grateful to PERTH, CANB and NSW herbaria for providing the much needed specimens, especially NSW for the permission to sample material for molecular studies.

\section{References}

Akhani H, Edwards G, Roalson EH (2007) Diversification of the Old World Salsoleae s.l. (Chenopodiaceae): molecular phylogenetic analysis of nuclear and chloroplast datasets and a revised classification. International Journal of Plant Sciences 168: 931-956. 
AUSLIG (Australian Surveying and Land Information Group) (1990) Atlas of Australian Resources, vol. 6: Vegetation.

Barker DG \& Greenslade PJM (1982) Evolution of the Flora and Fauna of arid Australia. (Peacock Publications: Adelaide)

Barlow BA (1981) The Australian Flora: its origin and evolution. Pp. 25-75 in George AS (ed.) Flora of Australia. (Griffin Press Limited: Netley, SA)

Bayer RJ, Greber DG \& Bagnall NH (2002) Phylogeny of Australian Gnaphalieae (Asteraceae) based on chloroplast and nuclear sequences, the trnL intron, $\operatorname{trnL} / \operatorname{trnF}$ intergenic spacer, matK and ETS. Systematic Botany 27: 801-814.

Beadle NCW (1981) Origins of the Australian angiosperm flora. Pp. 409-426 in Keast A (ed.) Ecological Biogeography of Australia. (Dr. W. Junk bv Publishers: The Hague)

Beard JS (1977) Tertiary evolution of the Australian flora in light of latitudinal movements of the continent. Journal of Biogeography 4: 111-118.

Benbow MC, Alley NF, Callan RA, Greenwood DR (1995) Geological history and palaeoclimate. Pp. 208-217 in Dexel JF \& Preiss WV (eds) The Geology of South Australia, the Phanerozoic, vol. 2. (Geological Survey of South Australia Bulletin 54: Adelaide)

BOM (Bureau of Meteorology, Australian Government) (2010) Climate Education (http://www. bom.gov.au/lam/climate/levelthree/ausclim/ausclim.htm)(Downloaded September 2010).

Bowler JM (1976) Aridity in Australia: age, origins and expressions in Aeolian landforms and sediments. Earth Science Reviews 12: 279-310.

Bowler JM (1982) Aridity in the late Tertiary and Quaternary of Australia. Pp. 35-45 in Barker WR \& Greenslade PJM (eds.) Evolution of the Flora and Fauna of Arid Australia. (Peacock Publications: Frewville, South Australia)

Burbidge NT (1960) The phytogeography of Australia. Australian Journal of Botany 8: 75-209.

Byrne M \& Hines B (2004) Phylogeographical analysis of cpDNA variation in Eucalyptus loxophleba (Myrtaceae). Australian Journal of Botany 52: 459-470.

Cabrera JF, Jacobs SWL \& Kadereit G (2009) Phylogeny of the Australian Camphorosmeae (Chenopodiaceae) and the taxonomic significance of the fruiting perianth. International Journal of Plant Sciences 170: 505-521.

Carolin RC (1981) A review and critique of studies on the phytogeography of Australia. Pp. 119-123 in Barker WR \& Greenslade PJM (eds.) Evolution of the Flora and Fauna of Arid Australia. (Peacock Publications: Frewville, South Australia)

Christophel DC (1989) Evolution of the Australian flora through the Tertiary. Plant Systematics and Evolution 162: 63-78.

Cracraft J (1991) Patterns of diversification within continental biotas: hierarchical congruence among the areas of endemism of Australian vertebrates. Australian Systematic Botany 4: $211-27$.

Crisp MD, Linder HP \& Weston PH (1995) Cladistic biogeography of plants in Australia and New Guinea: Congruent pattern reveals two endemic tropical tracks. Systematic Biology 44: 457-473.

Crisp MD, West JG \& Linder HP (1999) Biogeography of the terrestrial flora. Pp. 321-368 in Flora of Australia, vol. 1, 2nd edition. (ABRS/CSIRO Australia: Melbourne)

Donoghue MJ, Bell CD \& Li J (2001) Phylogenetic patterns in northern hemisphere plant geography. International Journal of Plant Sciences 162: S41-S52.

Drovetski SV (2003) Plio-Pleistocene climatic oscillations, Holarctic biogeography and speciation in an avian subfamily. Journal of Biogeography 30: 1173-1181.

Frakes LA (1999) Evolution of Australian Environments. Pp. 163-203 in Orchard AE (ed.) Flora of Australia, vol. 1, 2nd edition. (ABRS/CSIRO Australia: Melbourne)

Guo Z, Ruddiman WF, Hao Q, Wu HB, Qiao YS, Zhu RX, Peng S, Wei JJ, Yuan BY \& Liu T (2002) Onset of Asian desertification by 22 myr ago inferred from loess deposits in China. Nature 416: $159-163$. 
Hill RS, Truswell EM, McLoughlin S, Dettmann ME (1999) Evolution of the Australian flora: fossil evidence. Pp. 251-320 in Orchard AE (ed.) Flora of Australia, vol. 1, 2nd edition. (ABRS/CSIRO Australia: Melbourne)

Hobbs JE, Lindesay JA, Bridgman HA (1998) Climates of Southern Continents. (Wiley: Chichester, England)

Kadereit G, Ball P, Beer S, Freitag H, Mucina L, Sokoloff D, Teege P, Yaprak \& AE (2007) A taxonomic nightmare comes true: phylogeny and biogeography of glassworts (Salicornia L., Chenopodiaceae). Taxon 56: 1143-1170.

Kadereit G, Borsch T, Weising K \& Freitag H (2003) Phylogeny of Amaranthaceae and Chenopodiaceae. International Journal of Plant Sciences 164: 959-986.

Kadereit G \& Freitag H (2011) Molecular phylogeny of Camphorosmeae (Camphorosmoideae, Chenopodiaceae): implications for biogeography, evolution of $\mathrm{C}_{4}$ photosynthesis and taxonomy. Taxon 60(1): in press.

Kadereit G, Gotzek D, Jacobs SWL \& Freitag H (2005) Origin and age of Australian Chenopodiaceae. Organisms, Diversity and Evolution 5: 59-80.

Kadereit, G, Mavrodiev EV, Zacharias E \& Sukhorukov AP (2010) Molecular phylogeny of Atripliceae (Chenopodioideae, Chenopodiaceae) - implications for systematics, biogeography, flower and fruit evolution and the origin of $\mathrm{C}_{4}$-photosynthesis. American Journal of Botany 97.

Keast A (1959) The Australian Environment. Pp. 9-35 in Keast A, Crocker RL, Christian CS (eds.) Biogeography and Ecology in Australia. (Dr. W Junk: The Hague)

Kuhnt W, Holburn A, Hall R, Zuvela M, Käse R (2004) Neogene history of the Indonesian flow through. Pp. 252-282 in Clift PD, Kuhnt W, Wang P, Hayes D (eds) Continent-Ocean interactions within East Asian Marginal Seas: Geophysical Monograph, vol. 149. (American Geophysical Union)

Markgraf V, McGlone M \& Hope G (1995) Neogene paleoenvironmental and paleoclimatic change in southern temperate ecosystems - a southern perspective. Trends in Ecology \& Evolution 10: 143-147.

Martin HA (1978) Evolution of the Australian flora and vegetation through the Tertiary: Evidence from pollen. Alcheringa 2: 181-202.

Martin HA (1981) The Tertiary flora. Ecological Biogeography of Australia. Pp. 393-406 in Keast A (ed.) Ecological Biogeography of Australia. (Dr. W. Junk bv Publishers: The Hague)

Martin HA (1998a) Tertiary climatic evolution and the development of aridity in Australia. Proceedings of the Linnean Society of NSW 119: 115-136.

Martin HA (1998b) Late Cretaceous-Cainozoic palynology of the Poonarunna No. 1 Well, Central Australia. Transactions of the Royal Society of South Australia 122: 89-138.

Martin HA (2006) Cenozoic climatic change and the development of the arid vegetation in Australia. Journal of Arid Environments 66: 533-563.

Martin HA \& McMinn A (1994) Late Cainozoic vegetation history of north-western Australia from the palynology of a deep sea core (ODP site 765). Australian Journal of Botany 42: 95-102.

McLoughlin S (2001) The breakup history of Gondwana and its impact on pre-Cenozoic floristic provincialism. Australian Journal of Botany 49: 27-300.

Nix HA (1981) The environment of Terra Australis. Pp. 103-133 in Keast A (ed.) Ecological Biogeography of Australia. (Dr. W. Junk bv Publishers: The Hague)

Posada D \& Crandall KA (1998) Modeltest: testing the model of DNA substitution. Bioinformatics 14: 817-818.

Quilty PG (1982) Mesozoic and Cainozoic history of Australia as it affects the Australian biota. Pp. 7-56 in Cogger HG \& Cameron EE (eds) Arid Australia. (Australian Museum: Sydney)

Ronquist F (1996) DIVA, v1.1. (http://www.ebc.uu.se/systzoo/research/diva/diva.html) (Downloaded February 2006)

Ronquist F (1997) Dispersal-vicariance analysis: a new approach to the quantification of historical biogeography. Systematic Biology 46: 1995-203. 
Sanderson MJ (1997) A nonparametric approach to estimating divergence times in the absence of rate constancy. Molecular Biology and Evolution 14: 1218-1231.

Sanderson MJ (2002) Estimating absolute rates of molecular evolution and divergence time: A penalized likelihood approach. Molecular Biology and Evolution 19: 101-109.

Sanderson MJ (2004) r8s, version 1.70. (http://ginger.ucdavis.edu/r8s) (Downloaded February 2006)

Schodde R (1989) Origins, radiations and sifting in the Australasian biota - changing concepts from new data and old. Australian Systematic Botany Society Newsletter 60: 2-11.

Singh G \& Luly J (1991) Changes in vegetation and seasonal climate since the last full glacial at Lake Frome, South Australia. Palaeogeography, Palaeoclimatology, Palaeoecology 84: 75-86.

Stagg HMJ \& Willcox JB (1992) A case for Australia-Antarctica separation in the Neocomian (ca. $125 \mathrm{Ma})$. Tectonophysics 210: 21-32.

Stein R \& Robert C (1986) Siliclastic sediments at Sites 588, 590 and 591: Neogene and Paleogene evolution in the southwest Pacific and Australian climate. Initial Reports of the Deep Sea Drilling Project 90: 1437-1455.

Swofford DL (2002) PAUP*. Phylogenetic Analysis Using Parsimony (*and Other Methods). Version 4 Beta10. Sinauer Associates, Sunderland, Massachusetts.

Veevers JJ (1986) Breakup of Australia and Antarctica estimated as mid-Cretaceous (95 $\pm 5 \mathrm{Ma}$ ) from magnetic and seismic data at the continental margin. Earth and Planetary Science Letters 77: 91-99.

Veevers JJ (2000) Change of tectono-stratigraphic regime in the Australian plate during the 99 $\mathrm{Ma}$ (mid-Cretaceous) and $43 \mathrm{Ma}$ (mid-Eocene) swerves of the Pacific. Geology 28: 47-50.

Voelker G (1999) Dispersal, vicariance, and clocks: historical biogeography and speciation in a cosmopolitan passerine genus (Anthus: Motacillidae). Evolution 53: 1536-1552.

Wilson PG (1984) Chenopodiaceae. Pp. 81-316 in George AS (ed.) Flora of Australia, vol. 4. (Australian Government Publishing Service: Canberra)

Zacharias EH \& Baldwin BG (2010) A molecular phylogeny of North American Atripliceae (Chenopodiaceae), with implications for floral and photosynthetic pathway evolution. Systematic Botany 35: 839-857.

Zheng H, Wyrwoll KH, Li Z \& Powell CM (1998) Onset of aridity in southern West Australia a preliminary palaeomagnetic appraisal. Global and Planetary Change 18: 175-187.

Zink RM, Blackwell-Rago RC \& Ronquist F (2000) The shifting roles of dispersal and vicariance in biogeography. Proceedings of the Royal Society of London. Series B: Biological Sciences 267: 497-503. 